\title{
Health outcomes in offspring born to survivors of childhood cancers following assisted reproductive technologies
}

\author{
Greta Sommerhäuser ${ }^{1} \cdot$ Anja Borgmann-Staudt ${ }^{1}$ (D) Kathy Astrahantseff $^{1} \cdot$ Katja Baust $^{2} \cdot$ Gabriele Calaminus $^{2}$. \\ Ralf Dittrich $^{3}$ - Marta J. Fernández-González ${ }^{1} \cdot$ Heike Hölling $^{4} \cdot$ Charlotte J. König $^{1} \cdot$ Ralph Schilling ${ }^{1,5}$. \\ Theresa Schuster $^{1} \cdot$ Laura Lotz $^{3}$ • Magdalena Balcerek ${ }^{1,6}$
}

Received: 29 May 2020 / Accepted: 15 August 2020 / Published online: 26 August 2020

(C) The Author(s) 2020

\begin{abstract}
Purpose An increasing number of childhood cancer survivors are using assisted reproductive technologies (ART) to overcome treatment-related fertility impairment. We report perinatal and health outcomes of offspring born to survivors following ART. Methods The FeCt Multicenter Offspring Study surveyed the health of offspring of childhood cancer survivors. Health outcomes in offspring born to survivors following ART $(n=57,4.6 \%)$ or after spontaneous conception $(n=1182)$ were assessed in the German cohort ( $n=1239$ ) using bivariate analysis. Findings were put into the context of the general German population by health outcome assessment in 1:1 matched-pair analysis $(n=2478)$.

Results Nearly twice the survivors used ART compared with numbers reported for the German general population (4.6\% vs. 2.6\%). Successful pregnancies were achieved after a median of two cycles, mainly using non-cryopreserved oocytes/sperm. Multiple sibling births $(p<0.001,28.1 \%$ vs. 3.0\%) and low birth weight $(p=0.008$; OR $=2.659,95 \% \mathrm{CI}=1.258-5.621)$ occurred significantly more often in offspring born to survivors who utilized ART than spontaneously conceived children, whereas similar percentages were born preterm or too small for their gestational age. ART did not increase the prevalence of childhood cancer or congenital malformations in offspring born to survivors.

Conclusion ART use by childhood cancer survivors was successful with both fresh and cryopreserved oocytes/sperm, and did not influence perinatal health or health outcomes when known confounders were taken into account.

Implications for Cancer Survivors Oncofertility is an important component of patient care. Our study implicates that the utilization of ART by adult survivors of childhood cancer does not put offspring at additional risk for adverse perinatal or health outcomes.
\end{abstract}

Keywords Assisted reproductive technologies $\cdot$ Childhood cancer survivor $\cdot$ Pediatric cancer $\cdot$ Infertility $\cdot$ Offspring

Electronic supplementary material The online version of this article (https://doi.org/10.1007/s11764-020-00929-0) contains supplementary material, which is available to authorized users.

Anja Borgmann-Staudt

anja.borgmann@charite.de

1 Department of Pediatric Oncology and Hematology, Charité-Universitätsmedizin Berlin, Freie Universität Berlin, Humboldt-Universität zu Berlin, and Berlin Institute of Health, Augustenburger Platz 1, 13353 Berlin, Germany

2 University Hospital Bonn (UKB), Venusberg-Campus 1, 53127 Bonn, Germany
3 Department of Obstetrics and Gynecology, Erlangen University Hospital, Friedrich-Alexander University of Erlangen-Nürnberg, Maximiliansplatz 2, 91054 Erlangen, Germany

4 Robert Koch-Institute Berlin, General-Papestr. 62-66, 12101 Berlin, Germany

5 Charité-Universitätsmedizin Berlin, Freie Universität Berlin, Humboldt-Universität zu Berlin, and Berlin Institute of Health, Institute for Biometry and Clinical Epidemiology (IBiKE), Charitéplatz 1, 10117 Berlin, Germany

6 Berlin Institute of Health (BIH), Anna-Louisa-Karsch-Straße 2, 10178 Berlin, Germany 


\section{Introduction}

Worldwide, $>5,000,000$ live births have been reported following assisted reproductive technologies (ART), mostly in vitro fertilization and intracytoplasmic sperm injection [1], with annual numbers rising [2]. In 2016, $2.6 \%$ of children in Germany were born following ART [3]. While the majority of children conceived by ART are born healthy, ART has been associated with a higher risk of adverse birth outcomes than spontaneous conception [4]. These include increased occurrences of adverse perinatal events [5], childhood cancer [6], congenital malformations [7] (including heart defects [8]), hypertension [9, 10], and asthma [11]. Hypotheses explaining these observations implicate pharmaceutically induced ovulation, micromanipulation during ART procedures, effects associated with increased incidence of multiple sibling births [4], and subfertility itself [12].

Infertility is a known late effect of cancer treatment in childhood [13-15], yet national $[16,17]$ and international $[18,19]$ guidelines on fertility protection have only been developed in recent years. An increasing number of childhood cancer survivors are employing ART to fulfill the wish for biological children [20]. Survivors report being anxious about the general health of future children and the possibility that their previous cancer treatment may increase the risk of cancer in offspring [21]. Studies have shown that offspring of nonhereditary childhood cancer survivors do not have an increased risk for malformations, genetic diseases, or nonhereditary cancers [22-24]. Yet, whether ART affects offspring health when used by childhood cancer survivors has not been specifically addressed.

Within our FeCt $t^{1}$ Multicenter Offspring Study, we compared perinatal outcomes and the prevalence of childhood cancer and congenital malformations, including heart defects, in children born to German survivors following ART and after spontaneous conception. To contextualize our findings, we also compared health outcomes in the survivor offspring cohort to children in the general German population.

\section{Methods}

\section{Design and participants}

Between 2013 and 2019, we conducted the FeCt Multicenter Offspring Study in Germany, Austria, Czech Republic, Poland, and Switzerland to survey childhood cancer survivors on health aspects of their biological children. The study was approved by the Charité local ethics committee (EA2/237/05, EA2/103/11) and the German Society for Pediatric Oncology

\footnotetext{
${ }^{1} \mathrm{FeCt}$, fertility after chemo- and radiation therapy in childhood and adolescence
}

and Hematology. Survey methods of the German cohort and our study questionnaire were published previously $[21,25$, 26]. Childhood cancer survivors identified as having biological children in the previously conducted nationwide studies, $\mathrm{FeCt}$ on survivor fertility $[21,26]$ and VIVE on somatic and psycho-social late effects in survivors [27], were contacted via the German Childhood Cancer Registry $(n=1340$, Supplemental Figure 1). Survivors of at least 18 years of age were included for study participation if informed consent was given. Participating survivors who had used ART were additionally interviewed by phone in June and July 2019 on details of their ART treatment and course of pregnancy. For comparison with the general German population, we drew data from the KiGGS Study (health examination survey for children and adolescents in Germany) conducted in 17,641 children by the Robert Koch Institute between 2003 and 2006 [28]. Survivor offspring $(n=1239)$ were matched 1:1 with children from the KiGGS collective using gender, age, and born as singletons versus as multiple siblings in a case-control design for matched-pair analysis.

\section{Variables}

In total, 46 items concerning diseases, pain, well-being, living conditions, diet, health-related behavior, healthcare utilization, and social determinants were measured. Core data for the participating survivors were available from the German Childhood Cancer Registry. Participating survivors reported whether children were conceived spontaneously or via ART (specifying type). World Health Organization definitions were used to describe perinatal outcomes (gestational age, birth weight, small for gestational age) [29] and to categorize congenital malformations including heart defects (International Classification of Disease, ICD-10) [29]. The International Classification of Childhood Cancer (ICCC-3) was used to specify cancer diagnoses [30]. Whether survivors' children had a cancer, malformation, or heart condition were surveyed by yes/no questions, and the diagnosis was further described in answer to "If yes, which?". Whether survivors (who used ART) received chemotherapy, radiotherapy, and/or stem cell transplantation to treat their cancers were available via cooperation with the completed $\mathrm{FeCt}$ and VIVE studies (Supplemental Figure 1). Cause and type of infertility and details about ART procedure and pregnancy/birth-related complications were queried via phone interview.

\section{Statistical methods}

Analyses were performed using IBM SPSS Statistics, Version 25. Questionnaires lacking child's gender, age or mode of conception, or (for comparability with the KiGGS cohort, age range $0-17$ years) describing children $\geq 18$ years at survey time were excluded from analyses (Supplemental Figure 1). 
To minimize the amount of missing data, a user-friendly questionnaire containing standardized and validated instruments from the KiGGS Study was designed and a pilot study was performed. Cases with missing data were omitted and remaining data were analyzed (listwise deletion). Survivor offspring group differences were nonparametrically tested (2-sided chisquare and Mann-Whitney $U$ tests for unpaired samples) with a 5\% significance level. Even though the number of offspring born to childhood cancer survivors following ART $(n=57)$ was small, post hoc calculation of statistical power revealed that the given sample size provided $80 \%$ power to detect group differences at the 5\% significance level and an odds ratio (OR) of 2.8 (medium effect) by logistic regression. Bivariate analyses were carried out using McNemar and Wilcoxon signed-rank tests for paired nonparametric samples with a significance level of $<5 \%$ to detect group differences. Effect sizes were calculated including unadjusted OR with 95\% confidence intervals (95\% CI) and Cohen's $d$ effect size [31] (thresholds: $0.2=$ small, $0.5=$ medium, $0.8=$ large). Binary logistic regression was carried out to estimate adjusted ORs with $95 \%$ CI in multivariate analyses to assess the intervariable dependencies of the sociodemographic factors, gender, age, migration background, and educational attainment of parents (rated low, medium, or high using CASMIN classification [32], as well as multiple sibling birth, smoking/ drinking habits during pregnancy, and parental estimation of their child's health). The age at diagnosis (grouped into 0-4, 5-9 and 10 or more years of age) and type of cancer (grouped into leukemia/lymphoma, brain tumors and extra-cranial solid tumors) in the parents were considered additional variables in multivariate analysis.

\section{Results}

\section{Participants}

We received responses from 852 German childhood cancer survivors (65.8\% of those contacted), who returned 1340 questionnaires for their children (Supplemental Figure 1). Responders were more likely to be female $(p<0.001)$ and moderately to highly educated $(p<0.001)$. Survivors' diagnoses, age at diagnosis, and at time of survey were equally distributed among survey participants and non-participants (Supplemental Table 1). Of the 1239 children born to childhood cancer survivors, 57 were conceived after ART (4.6\%) and were born, on average, closer to the time of survey (Table 1). Compared with those who spontaneously conceived, survivors using ART experienced more multiple sibling births, and none reported smoking or drinking during pregnancy. Survivors who utilized ART were older at cancer diagnosis, but parental cancer diagnoses were equally distributed between children born after ART or spontaneously conceived children (Table 1). Of 40 survivors who reported ART, we successfully interviewed 27 survivors $(67.5 \%$, Supplemental Figure 1) about their 44 children born after ART. Clinical records available for 24 interviewed survivors showed that all received chemotherapy, 12 had also received radiotherapy and one underwent bone marrow transplantation. In both female and male childhood cancer survivors, male factor infertility contributed more strongly to the necessity for ART in couples including a childhood cancer survivor (Table 2). The majority of survivors used fresh oocytes/ sperm for fertility treatment. In vitro fertilization/ intracytoplasmic sperm injection was successful after one cycle in half the couples; however, $18.2 \%$ (4/22 pregnancies in female survivors) required $\geq 3$ cycles. Most childhood cancer survivors that used ART reported spontaneous vaginal deliveries $(65.4 \%$ in female, $66.7 \%$ in male survivors), with only two emergency cesarean sections being reported (Table 2). Paired analysis of survivor offspring matched to children in the general German population (KiGGS cohort) showed a higher educational level in parents who survived childhood cancer than in the general population (Table 1). Survivors were also more careful about alcohol and tobacco use during pregnancy (Table 1).

\section{Perinatal outcomes}

We evaluated the prevalence of preterm birth, low birth weight, and small for gestational age in survivor offspring from the survey responses. Children born to survivors, whether following ART or spontaneous conception, were born to term (37 to $<42$ weeks of gestation, Table 3 ). The offspring born following ART, however, were delivered slightly but significantly earlier (mean 38.5 vs. 39.1 weeks of gestation, $p=0.028$; Cohen's $d 0.127$ ). While using ART did not significantly increase the risk for premature birth among childhood cancer survivors, bivariate analysis revealed that birth weight below $2500 \mathrm{~g}$ (low birth weight) was statistically more prevalent $(p=0.008 ; \mathrm{OR}=2.659,95 \% \mathrm{CI}=1.258-5.621$, Table 3). In multivariate analyses, however, differences in the prevalence of low birth weight between groups were no longer apparent (Supplementary Table 2). Preterm birth $(p<0.001 ; \mathrm{OR}=38.306,95 \% \mathrm{CI}=21.044-69.727)$ and congenital heart defects $(p=0.046 ; \mathrm{OR}=5.616,95 \% \mathrm{CI}=1.030$ 30.610) were confirmed to be confounding variables affecting the prevalence of low birth weight in our cohort. When birth weight was related to the respective gestational age to identify children born too small for gestational age $(<10$ th percentile), no differences were detected between survivor offspring born after ART or spontaneous conception (Table 3). Paired analysis with the general population (KiGGS children) revealed that survivor offspring were delivered at term, although marginally earlier (mean 39.0 vs. 39.3 weeks of gestation, $p=$ 0.036; Cohen's $d=0.065$, Table 3). Among survivor 


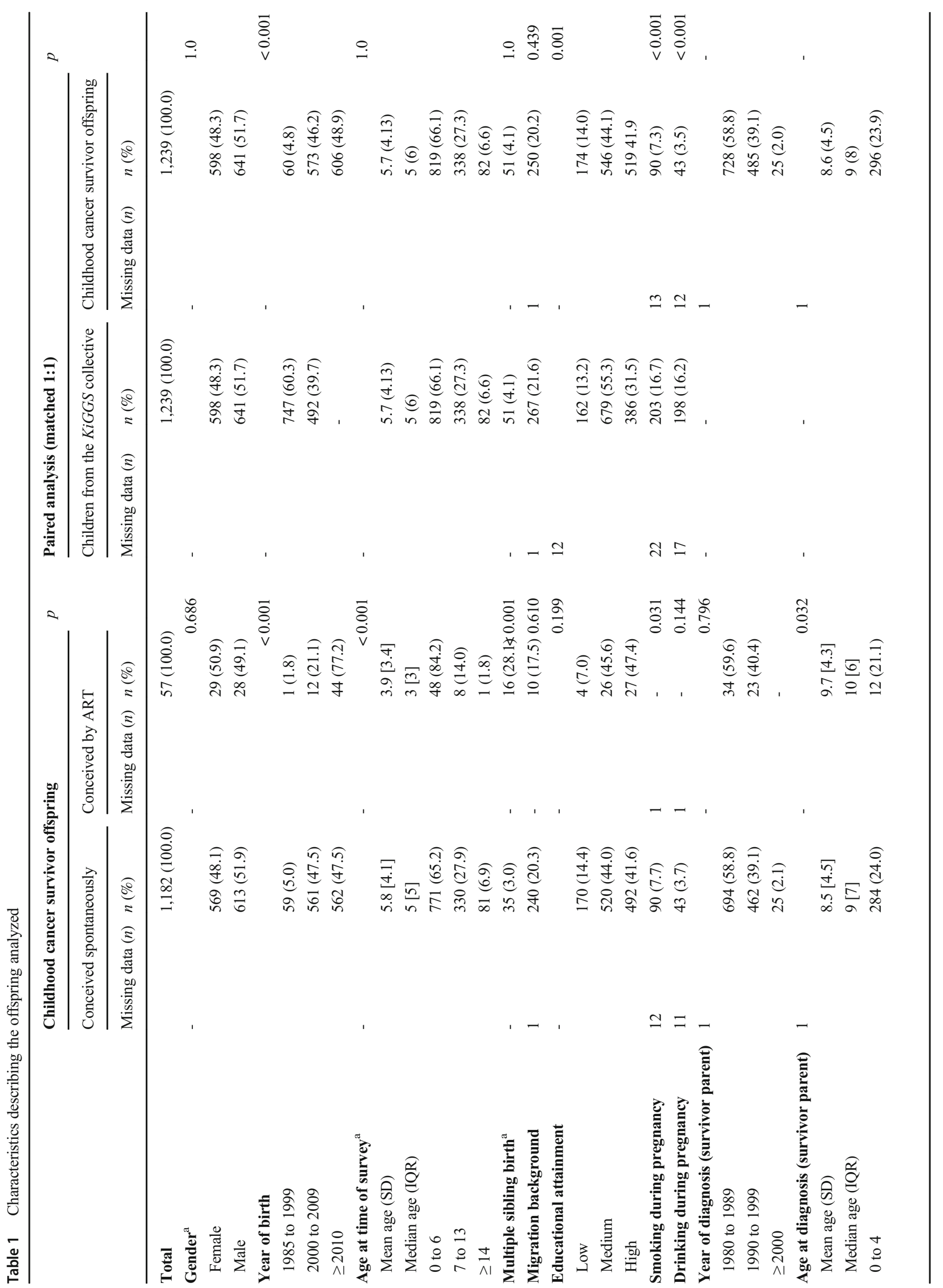




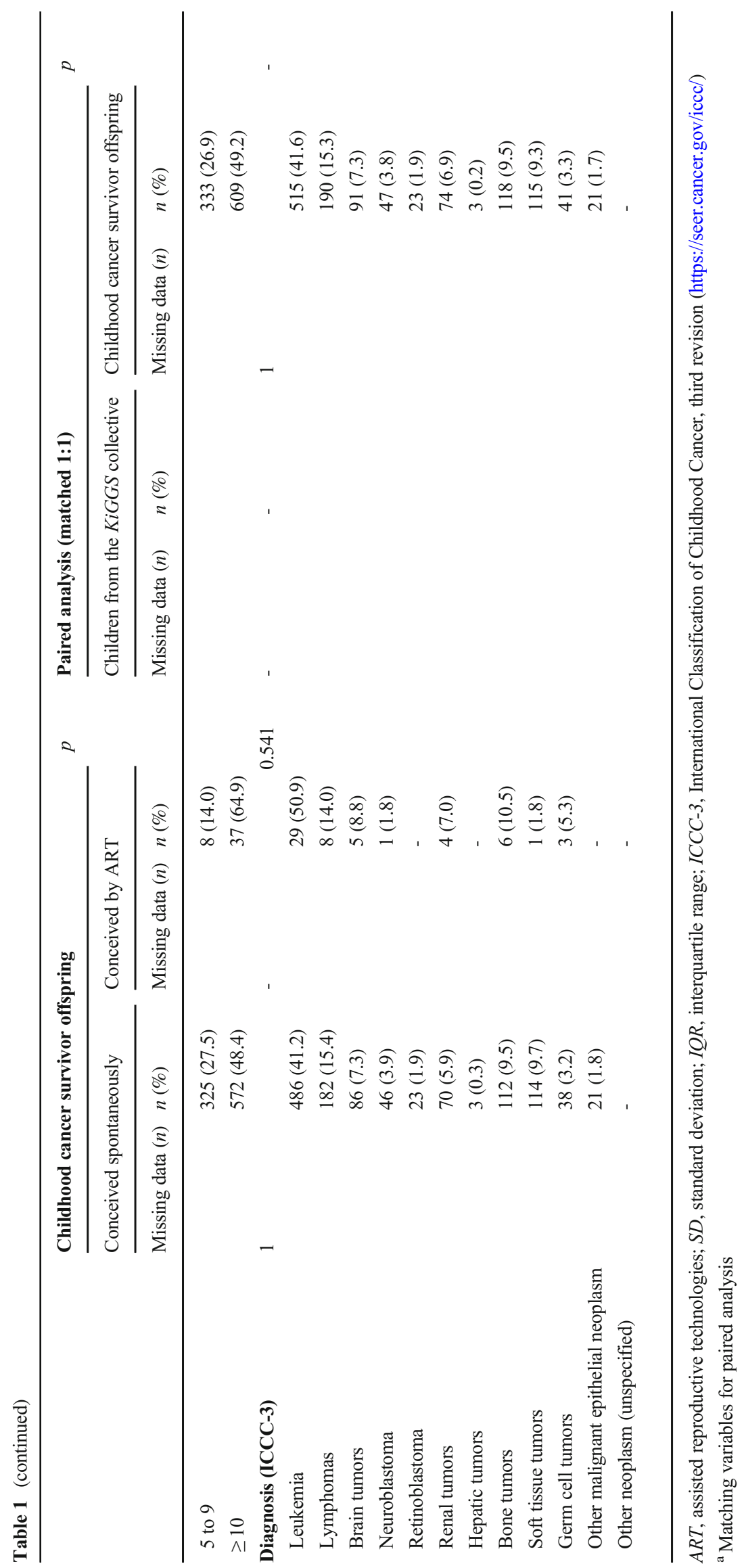


Table 2 ART characteristics (telephone interview)

Characteristics
Offspring born to survivors using ART

\begin{tabular}{|c|c|c|c|c|}
\hline \multicolumn{2}{|c|}{ Female survivor (parent) } & \multicolumn{2}{|c|}{ Male survivor (parent) } & \multirow[b]{2}{*}{$p$} \\
\hline Missing data $(n)$ & $n(\%)$ & Missing data $(n)$ & $n(\%)$ & \\
\hline & $26(100.0)$ & & $18(100.0)$ & \\
\hline \multirow[t]{3}{*}{-} & & - & & 0.179 \\
\hline & $12(46.2)$ & & $12(66.7)$ & \\
\hline & $14(53.8)$ & & $6(33.3)$ & \\
\hline \multirow[t]{4}{*}{1} & $10(40.0)$ & - & $14(77.8)$ & 0.014 \\
\hline & $7(28.0)$ & & $2(22.2)$ & \\
\hline & $15(60.0)$ & & $13(72.2)$ & \\
\hline & $3(12.0)$ & & $1(5.6)$ & \\
\hline \multirow[t]{7}{*}{-} & & - & & - \\
\hline & $3(11.5)$ & & $4(22.2)$ & \\
\hline & $17(65.4)$ & & $10(55.5)$ & \\
\hline & $3(11.5)$ & & - & \\
\hline & - & & $1(5.5)$ & \\
\hline & $3(11.5)$ & & $1(5.5)$ & \\
\hline & - & & $2(11.1)$ & \\
\hline \multirow[t]{4}{*}{-} & & - & & 0.025 \\
\hline & $23(88.5)$ & & $10(55.6)$ & \\
\hline & - & & $3(16.7)$ & \\
\hline & $3(11.5)$ & & $5(27.8)$ & \\
\hline \multirow[t]{4}{*}{1} & & - & & 0.187 \\
\hline & $10(45.5)$ & & $8(50.0)$ & \\
\hline & $8(36.4)$ & & $8(50.0)$ & \\
\hline & $4(18.2)$ & & - & \\
\hline \multirow[t]{5}{*}{-} & $8(30.8)$ & - & - & 0.009 \\
\hline & $3(11.5)$ & & - & \\
\hline & $3(11.5)$ & & - & \\
\hline & $1(3.8)$ & & - & \\
\hline & $1(3.8)$ & & - & \\
\hline \multirow[t]{10}{*}{-} & & - & & - \\
\hline & $17(65.4)$ & & $12(66.7)$ & \\
\hline & $1(3.8)$ & & $1(5.5)$ & \\
\hline & $3(11.5)$ & & $4(22.2)$ & \\
\hline & $4(15.4)$ & & - & \\
\hline & $1(3.8)$ & & $1(5.5)$ & \\
\hline & & & & 0.140 \\
\hline & $2(7.7)$ & & $3(16.7)$ & \\
\hline & 9 (34.6) & & $10(55.6)$ & \\
\hline & $15(57.7)$ & & $5(27.8)$ & \\
\hline \multirow[t]{3}{*}{-} & & & & 0.434 \\
\hline & $9.0[4.5]$ & & $10.2[4.3]$ & \\
\hline & $9.5[9.0]$ & & $12.5[6.5]$ & \\
\hline \multirow[t]{4}{*}{-} & & & & 0.565 \\
\hline & $18(69.2)$ & & $15(83.3)$ & \\
\hline & $3(11.5)$ & & $1(5.6)$ & \\
\hline & $5(19.2)$ & & $2(11.1)$ & \\
\hline
\end{tabular}


Table 2 (continued)

\begin{tabular}{|c|c|c|c|c|c|}
\hline \multirow{3}{*}{ Characteristics } & \multicolumn{4}{|c|}{ Offspring born to survivors using ART } & \multirow[b]{3}{*}{$p$} \\
\hline & \multicolumn{2}{|c|}{ Female survivor (parent) } & \multicolumn{2}{|c|}{ Male survivor (parent) } & \\
\hline & Missing data $(n)$ & $n(\%)$ & Missing data $(n)$ & $n(\%)$ & \\
\hline Treatment including radiotherapy & 3 & $11(47.8)$ & 1 & $7(41.2)$ & 0.676 \\
\hline Chemotherapy only & & $12(52.2)$ & & $10(58.8)$ & \\
\hline Chemo- and radiotherapy & & $11(47.8)$ & & $5(29.4)$ & \\
\hline Chemotherapy, radiotherapy and BMT & & - & & $2(11.8)$ & - \\
\hline Age at birth of offspring (in total) & - & & - & & 0.001 \\
\hline Mean age (SDF) & & $31.1[2.5$ & & $35.0[3.7]$ & \\
\hline Median age (IQR) & & $31[3.3$ & & $34[6.5]$ & \\
\hline Partner's age at birth of offspring (in total) & - & & - & & 0.032 \\
\hline Mean age (SDF) & & $35.6[4.9]$ & & $32.6[2.3]$ & \\
\hline Median age (IQR) & & $36[9.25]$ & & $32[3.0]$ & \\
\hline
\end{tabular}

$A R T$, assisted reproductive technologies; IVF, in vitro fertilization; ICSI, intracytoplasmic sperm injection; TESE, testicular sperm extraction; IUI, intrauterine insemination; $B M T$, bone marrow transplant; $S D$, standard deviation; $I Q R$, interquartile range

offspring, the risk of prematurity $(<37$ weeks of gestation, $p=$ $0.008 ; \mathrm{OR}=1.701,95 \% \mathrm{CI}=1.253-2.308)$ and low birth weight $(<2500 \mathrm{~g}, p=0.047$; OR $=1.431,95 \% \mathrm{CI}=1.020$ 2.007) was slightly but significantly elevated compared with the general population. Multivariate analyses confirmed group differences for prematurity $(p<0.001 ; \mathrm{OR}=2.002,95 \% \mathrm{CI}=$ 1.395-2.874), but not for low birth weight which was instead shown to be influenced by the epidemiologically known confounders, prematurity, and multiple sibling births [33] (Supplementary Table 2). The prevalence of being born too small for gestational age did not differ between survivor offspring and children in the general population.

\section{Prevalence of childhood cancer}

All childhood cancer survivors surveyed submitted information about cancer occurrences in their children. Although eight children born to survivors $(0.6 \%)$ were diagnosed with cancer before the age of 18 (including two retinoblastomas in children with hereditary predispositions), none of the affected children were born following ART (Table 4). Among the children from the $K i G G S$ cohort used in paired analysis, one child was diagnosed with a brain tumor and a second child with renal tumor $(0.2 \%, p=0.180)$. This comparison indicates that childhood cancer prevalence is no different in survivor offspring than in the general German population.

\section{Prevalence of congenital malformations and heart defects}

The childhood cancer survivors surveyed also submitted information about the occurrence of congenital malformations and heart defects in their offspring. Neither congenital malformations nor heart defects were more prevalent in survivor offspring born following ART compared with those spontaneously conceived (Table 4). The surveyed survivors reported 75 diagnoses of congenital malformations in 71 offspring of the 1224 offspring informed on in the survey (5.8\%). In the paired analysis for children from the general German population (KiGGS cohort), 130 diagnoses of congenital malformations were reported in 119 children, yielding an even higher prevalence for congenital malformations $(11.1 \%$, $p<0.001 ; \mathrm{OR}=0.393,95 \% \mathrm{CI}=0.284-0.544$, Table 4). The slightly higher prevalence for congenital malformations in the KiGGS cohort remained significant $(p=0.002, \mathrm{OR}=$ $0.538,95 \% \mathrm{CI}=0.364-0.796)$ in multivariate analyses (Supplementary Table 3). Congenital malformations were shown to be associated with a lower parental estimation of the child's overall health ("very good" $p<0.001 ; \mathrm{OR}=$ $0.312,95 \% \mathrm{CI}=0.161-0.604)$. Significantly more congenital heart defects (bivariate analysis: $p=0.049$; $\mathrm{OR}=0.592,95 \%$ $\mathrm{CI}=0.350-1.002$ ) occurred in the general population, with 38 diagnoses in $35 \mathrm{KiGGS}$ children reported (total $=1071,3.3 \%$ ) in comparison with 29 diagnoses in 24 survivor offspring (total $=1224,2.0 \%$, Table 4 ). Multivariate analysis, however, did not confirm this higher prevalence for congenital heart defects in KiGGS children (Supplementary Table 3). The prevalence of congenital malformations or heart defects was not increased in offspring of childhood cancer survivors in the surveyed cohort in any group comparisons conducted.

\section{Discussion}

Here, we specifically investigate the impact of ART on the health of offspring born to childhood cancer survivors using 


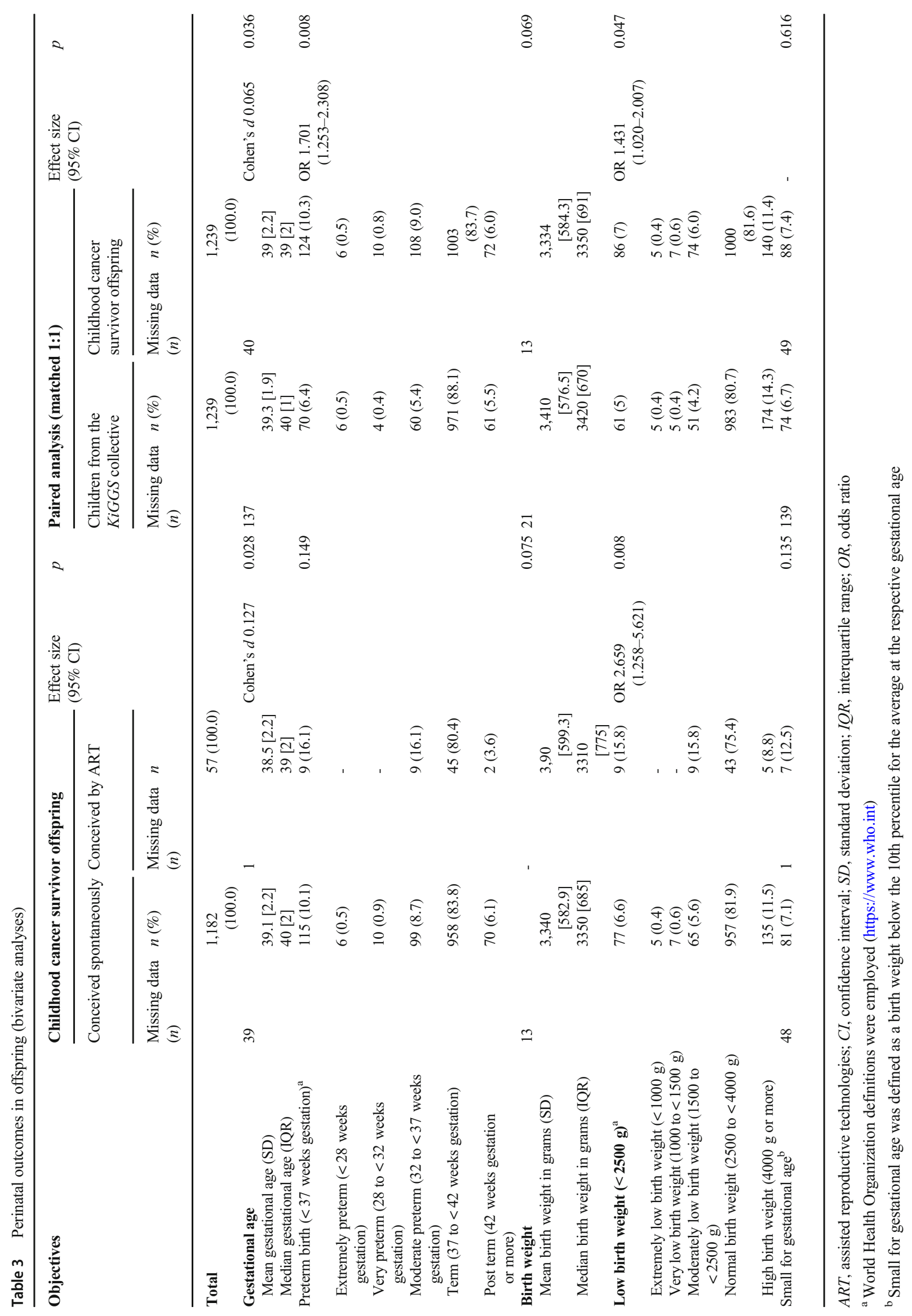




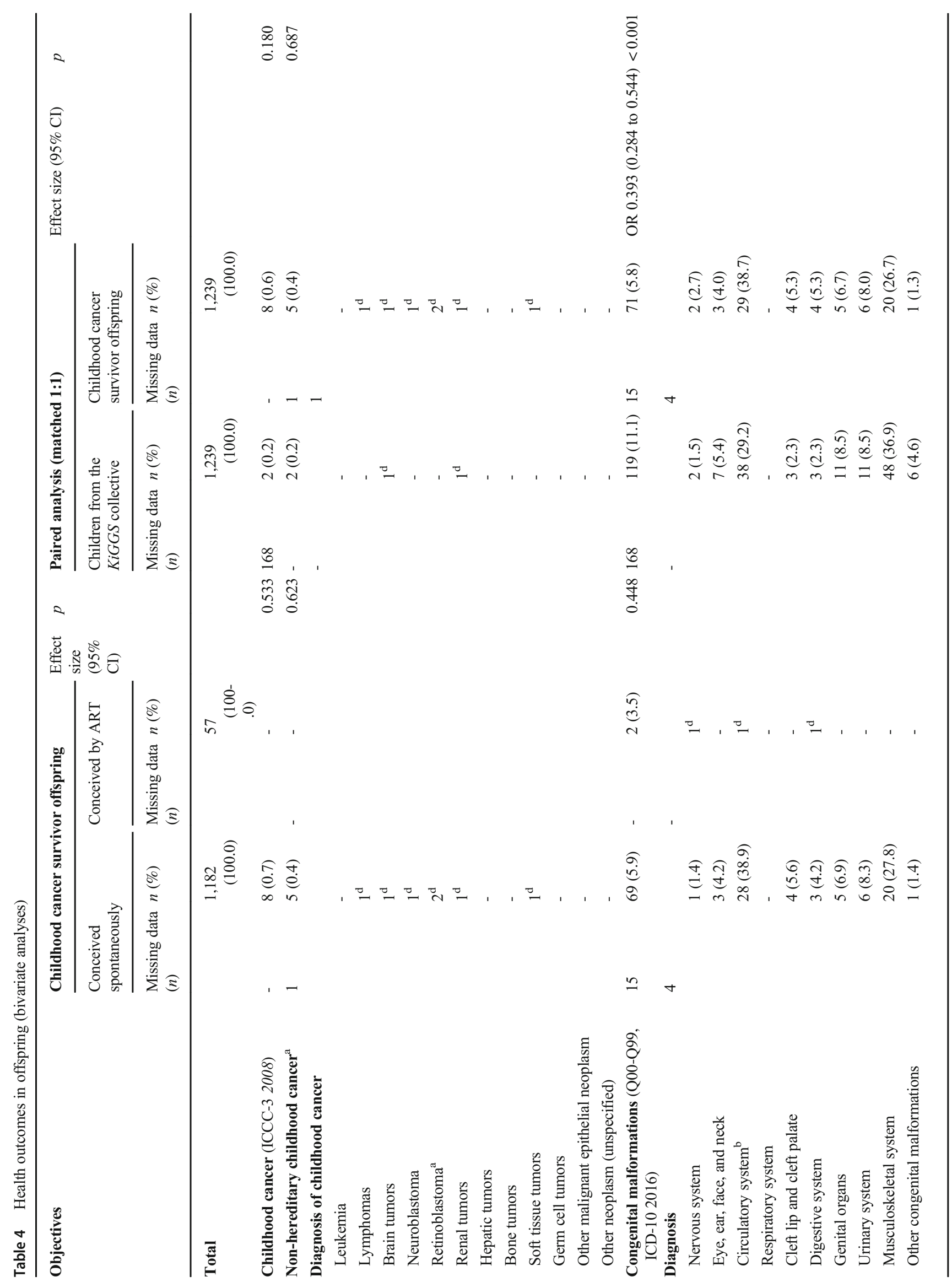




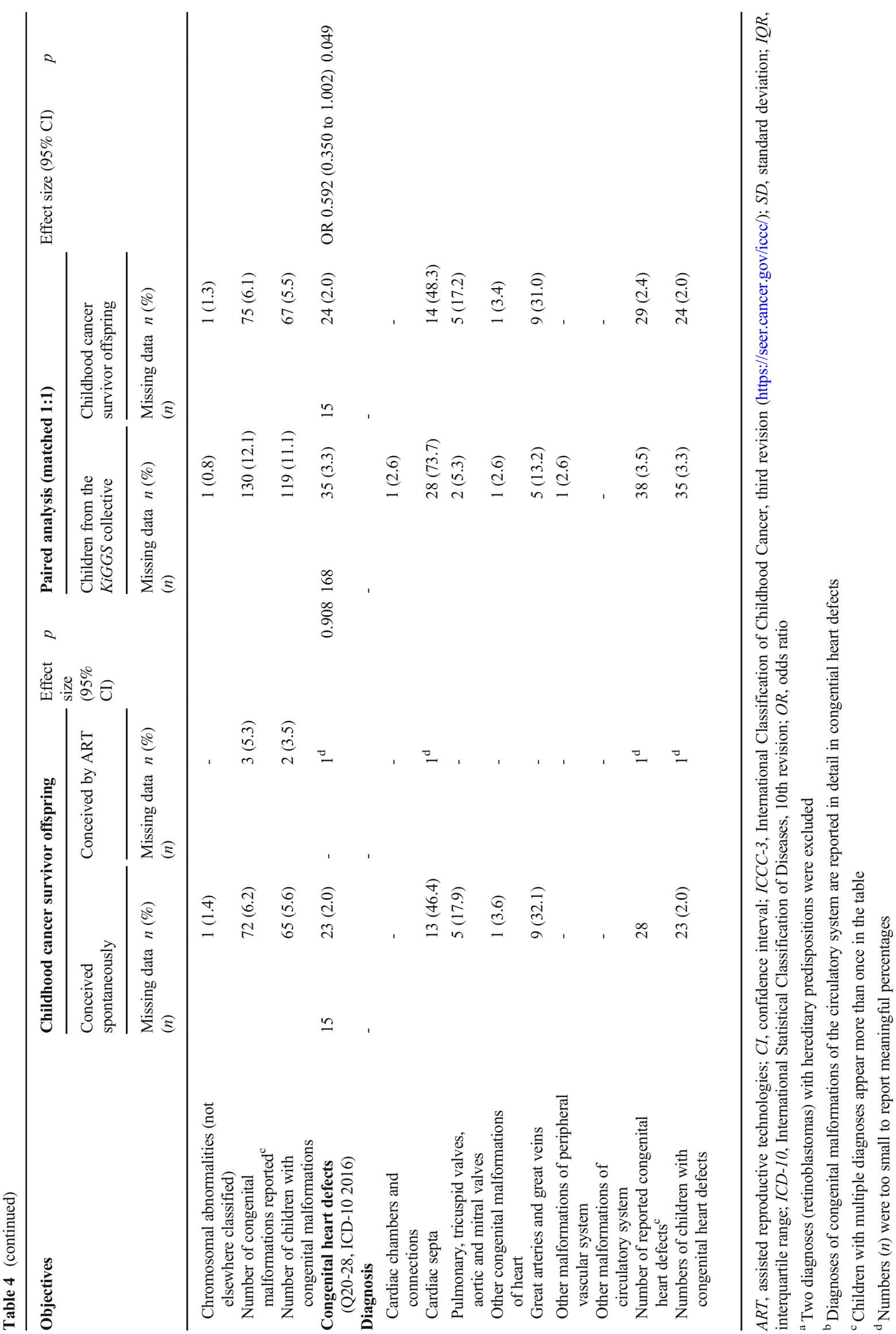


the only survey information published to date that was tailored to this question. Nearly twice the childhood cancer survivors used ART in our surveyed cohort (4.6\%) compared with numbers reported by the German In Vitro Fertilization Registry (2.6\%) [34]. This distribution parallels findings from Melin et al., who compared fertility treatments among female survivors of adult cancer and their siblings (5.2\% vs. 2.8\%) [35]. While current guidelines recommend fertility preservation before cancer treatment [36], patients in our cohort were treated (1980-1999) before its routine implementation. Only few patients cryopreserved oocytes/sperm prior to cancer treatment. In line with results from a recent European study [37], more male survivors cryopreserved, likely because sperm collection is less invasive and costly, but possibly also due to differences in counseling [38]. Our data showed that even in cases lacking pretreatment oocytes/sperm cryopreservation, successful ART pregnancies occurred in childhood cancer survivors. The increasing numbers of childhood cancer survivors who turn to ART [34] stress the importance of establishing an information base from which to counsel childhood cancer patients and survivors.

Our analyses revealed that the prevalence of multiple sibling births after ART was nearly tenfold higher than for children conceived spontaneously ( $28.1 \%$ vs. $3 \%)$. The higher prevalence of multiple sibling births after ART parallels the $34 \%$ reported for the general population in 2016 by the German In Vitro Fertilization Registry [34] and is in line with the $31.5 \%$ prevalence reported in 2016 in the USA [39]. Recent studies describe a mediating effect of multiple sibling births after ART on adverse obstetric outcomes [4, 5], indicating relevance for health also reflected in our findings from multivariate analyses on perinatal outcomes $(p<0.001$; $\mathrm{OR}=3.902,95 \% \mathrm{CI}=1.804$ to 8.441 , Supplementary Table 1). When known confounders including multiple sibling birth were taken into account $[4,5,40-43]$, perinatal outcomes were no different in survivor offspring, whether conceived after ART or spontaneously. We detected a modest increase in the prevalence for moderate preterm birth $(32$ to $<$ 37 weeks of gestation) in childhood cancer survivors compared to the KiGGS cohort, as a representative for the general German population. These findings are reassuring, since most medical consequences occur in very $(28$ to $<32$ weeks of gestation) or extremely ( $<28$ weeks of gestation) preterm infants [44]. Recent studies have cited long-term treatment effects as a possible source for their detected increased prevalence of adverse pregnancy outcomes in childhood cancer survivors. Van de Loo et al. and van Dorp et al. both found that childhood cancer survivors exposed to radiation were at higher risk for preterm delivery and low birth weight [24, 45]. The majority of survivors in our collective $(58.7 \%)$ were treated in the 1980s, typically receiving higher doses of radiation and alkylating agents (in multiagent chemotherapy schedules) than are currently used [46]. Against this backdrop of progressively reduced toxicity regimens, our findings appear particularly reassuring for patients treated with the less toxic protocols for childhood cancer today. Our study confirms the known increase in multiple sibling births following ART and indicates that prevalence was no higher in childhood cancer survivors than in the general German population. Adverse obstetric outcomes in survivors, as described by preceding studies, were only reflected by a small increase of moderate preterm births in our survivor cohort.

We found that ART did not raise the prevalence of childhood cancer among survivor offspring. In this respect, currently available data collected for the general population are not consistent. Williams et al. reported no increase in the overall risk for cancer among 106,013 children conceived through ART in the British general population, while the risk for hepatoblastoma and rhabdomyosarcoma appeared slightly increased [47]. Likewise, Spaan et al. reported no increase in the overall cancer risk among 24,269 children conceived after ART in the general Dutch population after a median followup of 21 years [48]. A meta-analysis of 25 cohort and casecontrol studies published in 2013, however, calculated a slightly elevated overall risk for cancer in children born after ART $(\mathrm{RR}=1.33,95 \% \mathrm{CI}=1.08-1.63)$ [49]. The authors pointed out that subfertility and potential epigenetic defects in the gametes, rather than the ART procedure itself, might be the most important predisposing factor for childhood cancer underlying these data [49]. While a meta-analysis by Hoorsan et al. from 2017 arrived at a 53\% higher risk for congenital malformations following ART in the general population [50], our data showed no increased risk for congenital malformations or heart defects among offspring born to childhood cancer survivors who used ART. Hoorsan et al. discuss genetic characteristics and conditions specifically occurring in infertile couples as causative, which may differ from characteristics of our study population. When comparing the prevalence of childhood cancer and congenital malformations in survivor offspring with children from the KiGGS Study, whether conceived by ART or spontaneous conception, our study confirmed findings from large studies [22-24], that showed no higher prevalence for childhood cancer in survivor offspring than in children in the general population. Similarly, the prevalence of congenital malformations, including heart defects, was not elevated in offspring born to our survivor cohort than the reported prevalence in the general population, in line with currently available data [51-55]. Our findings in the survivor cohort and in comparisons with the general German population support that the use of ART by childhood cancer survivors does not put offspring at additional risk for adverse health outcomes including childhood cancer or congenital malformations.

The study setting and conduct feasibility among childhood cancer survivors in Germany posed certain limitations. Recruitment was based on previous surveys identifying 
survivors with biological children, potentially causing a selection bias. This approach was necessary to reduce the study burden for survivors, as required by the German Society for Pediatric Oncology and Hematology. The questionnaire-based setting could produce recall bias that could reduce data accuracy. However, all survivor parents had been treated according to standardized trial protocols, for which detailed treatment information was available through the German Society for Pediatric Oncology and Hematology. Although we were able to examine a number of potential mediating factors, we had no information on maternal age, body mass index, and infections during pregnancy, which are further factors influencing perinatal events [46, 56-58]. Missing data of the main outcomes were rare in survivor offspring: $1.79 \%(0.08-3.95 \%)$ but more prevalent in the KiGGS cohort: $10.78 \%(1.70 \%-13.56 \%)$. Although we have no indication of this, it cannot be ruled out with certainty that these were not completely at random. Despite the explorative character of this study, which does not allow for confirmatory conclusions, our analyses offer new insights into health issues in offspring born to childhood cancer survivors, and the high response rate reflects the strong interest shown by survivors in these issues. The small sample size of 57 survivor offspring born after ART was adequate to detect medium effects ( $d 0.5$ or higher). Future studies are needed to further explore the effect of ART within a larger population. Our study delivers encouraging results for survivors of childhood cancer that demonstrate that the vast majority of offspring born to survivors do not experience adverse perinatal outcomes or later health problems, independently of whether conception was spontaneous or required ART.

Acknowledgments The authors thank the participants of our FeCt Multicenter Offspring Study for participation, as well as the Robert Koch Institute (Berlin), and the German Childhood Cancer Registry for the good cooperation. The FeCt Multicenter Offspring Study was supported by the Madeleine Schickedanz Kinderkrebsstiftung, KINDerLEBEN e.V. Berlin, the (Junior) Clinician-Scientist Program of Charité-Universitätsmedizin Berlin, and Berlin Institute of Health and by a doctoral grant from the Deutsche Stiftung für junge Erwachsene mit Krebs.

Author contributions All authors contributed to the study conception and design. Material preparation, data collection, and analysis were performed by Anja Borgmann-Staudt, Magdalena Balcerek, Theresa Schuster, Ralph Schilling, and Greta Sommerhäuser. The first draft of the manuscript was written by Greta Sommerhäuser, Magdalena Balcerek, and Kathy Astrahantseff and all authors commented on previous versions of the manuscript. All authors read and approved the final manuscript.

Funding information Open Access funding provided by Projekt DEAL. This work was supported by the Madeleine Schickedanz-KinderKrebsStiftung and KINDerLEBEN e.V. Berlin to Anja Borgmann-Staudt, the (Junior) Clinician Scientist Program of Charité-Universitätsmedizin Berlin, and Berlin Institute of Health to Magdalena Balcerek and by a doctoral grant from the Deutsche Stiftung für Junge Erwachsene mit Krebs to Greta Sommerhäuser.
Data availability The datasets generated during and/or analyzed during the current study are available from the corresponding author on reasonable request.

\section{Compliance with ethical standards}

Conflict of interest The authors declare that they have no conflict of interest.

Ethics approval All procedures performed in studies involving human participants were in accordance with the ethical standards of the institutional research committee, Charité local ethics committee (EA2/237/05, EA2/103/11), and with the 1964 Helsinki declaration and its later amendments or comparable ethical standards. This article does not contain any studies with animals performed by any of the authors.

Consent to participate Informed consent was obtained from all individual participants included in the study.

Open Access This article is licensed under a Creative Commons Attribution 4.0 International License, which permits use, sharing, adaptation, distribution and reproduction in any medium or format, as long as you give appropriate credit to the original author(s) and the source, provide a link to the Creative Commons licence, and indicate if changes were made. The images or other third party material in this article are included in the article's Creative Commons licence, unless indicated otherwise in a credit line to the material. If material is not included in the article's Creative Commons licence and your intended use is not permitted by statutory regulation or exceeds the permitted use, you will need to obtain permission directly from the copyright holder. To view a copy of this licence, visit http://creativecommons.org/licenses/by/4.0/.

\section{References}

1. Chen M, Heilbronn LK. The health outcomes of human offspring conceived by assisted reproductive technologies (ART). J Dev Orig Health Dis. 2017;8(4):388-402. https://doi.org/10.1017/ s2040174417000228.

2. Kupka MS, Ferraretti AP, de Mouzon J, Erb K, D’Hooghe T, Castilla JA, et al. Assisted reproductive technology in Europe, 2010: results generated from European registers by ESHREdagger. Hum Reprod. 2014;29(10):2099-113. https://doi. org/10.1093/humrep/deu175.

3. Verona B, Czeromin U, Daniel F, Klaus F, Gnoth C, Kruessel J et al. German IVF Registry (D.I.R) Annual Report 2017. Journal fur Reproduktionsmedizin und Endokrinologie. 2018;15:217-50.

4. Liberman RF, Getz KD, Heinke D, Luke B, Stern JE, Declercq ER, et al. Assisted reproductive technology and birth defects: effects of subfertility and multiple births. Birth Defects Res. 2017;109(14): 1144-53. https://doi.org/10.1002/bdr2.1055.

5. Sullivan-Pyke CS, Senapati S, Mainigi MA, Barnhart KT. In vitro fertilization and adverse obstetric and perinatal outcomes. Semin Perinatol. 2017;41(6):345-53. https://doi.org/10.1053/j.semperi. 2017.07.001.

6. Reigstad MM, Oldereid NB, Omland AK, Storeng R. Literature review on cancer risk in children born after fertility treatment suggests increased risk of haematological cancers. Acta Paediatr. 2017;106(5):698-709. https://doi.org/10.1111/apa.13755.

7. Chen L, Yang T, Zheng Z, Yu H, Wang H, Qin J. Birth prevalence of congenital malformations in singleton pregnancies resulting from in vitro fertilization/intracytoplasmic sperm injection worldwide: a 
systematic review and meta-analysis. Arch Gynecol Obstet. 2018;297(5):1115-30. https://doi.org/10.1007/s00404-018-4712$\mathrm{x}$.

8. Giorgione V, Parazzini F, Fesslova V, Cipriani S, Candiani M, Inversetti A, et al. Congenital heart defects in IVF/ICSI pregnancy: systematic review and meta-analysis. Ultrasound Obstet Gynecol. 2018;51(1):33-42. https://doi.org/10.1002/uog.18932.

9. Guo XY, Liu XM, Jin L, Wang TT, Ullah K, Sheng JZ, et al. Cardiovascular and metabolic profiles of offspring conceived by assisted reproductive technologies: a systematic review and metaanalysis. Fertil Steril. 2017;107(3):622-31.e5. https://doi.org/10. 1016/j.fertnstert.2016.12.007.

10. Meister TA, Rimoldi SF, Soria R, von Arx R, Messerli FH, Sartori $\mathrm{C}$, et al. Association of assisted reproductive technologies with arterial hypertension during adolescence. J Am Coll Cardiol. 2018;72(11):1267-74. https://doi.org/10.1016/j.jacc.2018.06.060.

11. Carson C, Sacker A, Kelly Y, Redshaw M, Kurinczuk JJ, Quigley MA. Asthma in children born after infertility treatment: findings from the UK Millennium Cohort Study. Hum Reprod. 2013;28(2):471-9. https://doi.org/10.1093/humrep/des398.

12. Lu YH, Wang N, Jin F. Long-term follow-up of children conceived through assisted reproductive technology. J Zhejiang Univ Sci B. 2013;14(5):359-71. https://doi.org/10.1631/jzus.B1200348.

13. Balcerek M, Reinmuth S, Hohmann C, Keil T, Borgmann-Staudt A. Suspected infertility after treatment for leukemia and solid tumors in childhood and adolescence. Dtsch Arztebl Int. 2012;109(7): 126-31. https://doi.org/10.3238/arztebl.2012.0126.

14. Green DM, Kawashima T, Stovall M, Leisenring W, Sklar CA, Mertens AC, et al. Fertility of female survivors of childhood cancer: a report from the childhood cancer survivor study. J Clin Oncol. 2009;27(16):2677-85. https://doi.org/10.1200/jco.2008.20.1541.

15. Lehmann V, Chemaitilly W, Lu L, Green DM, Kutteh WH, Brinkman TM, et al. Gonadal functioning and perceptions of infertility risk among adult survivors of childhood cancer: a report from the St Jude Lifetime Cohort Study. J Clin Oncol. 2019;37(11):893902. https://doi.org/10.1200/jco.18.00965.

16. AWMF. S1 Leitlinie 025-034. Beeinträchtigung der Gonadenfunktion nach Chemo- und Strahlentherapie im Kindesund Jugendalter: Risiken, Diagnostik, Prophylaxe- und Behandlungsmöglichkeiten. 2015. https://www.awmf.org/ leitlinien/detail/11/025-034.html.

17. Dittrich R, Kliesch S, Schüring A, Balcerek M, Baston-Büst DM, Beck R, et al. Fertility preservation for patients with malignant disease. Guideline of the DGGG, DGU and DGRM (S2k-level, AWMF registry no. 015/082, November 2017)-recommendations and statements for girls and women. Geburtshilfe Frauenheilkd. 2018;78(6):567-84. https://doi.org/10.1055/a-0611-5549.

18. Skinner R, Mulder RL, Kremer LC, Hudson MM, Constine LS, Bardi E, et al. Recommendations for gonadotoxicity surveillance in male childhood, adolescent, and young adult cancer survivors: a report from the International Late Effects of Childhood Cancer Guideline Harmonization Group in collaboration with the PanCareSurFup Consortium. Lancet Oncol. 2017;18(2):e75-90. https://doi.org/10.1016/s1470-2045(17)30026-8.

19. Oktay K, Harvey BE, Partridge AH, Quinn GP, Reinecke J, Taylor HS, et al. Fertility preservation in patients with cancer: ASCO clinical practice guideline update. J Clin Oncol. 2018;36(19):19942001. https://doi.org/10.1200/jco.2018.78.1914.

20. Melin J, Madanat-Harjuoja L, Hirvonen E, Seppa K, Malila N, Pitkaniemi J, et al. Use of fertility drugs in early-onset female cancer survivors-a Finnish register-based study on 8,929 survivors. Int J Cancer. 2020;146(3):829-38. https://doi.org/10.1002/ijc.32346.

21. Balcerek M, Schilling R, Schlack R, Borgmann-Staudt A. Nationwide survey on the health of offspring from former childhood cancer patients in Germany. Klin Padiatr. 2015;227(6-7): 350-4. https://doi.org/10.1055/s-0035-1565082.
22. Shliakhtsitsava K, Romero SAD, Dewald SR, Su HI. Pregnancy and child health outcomes in pediatric and young adult leukemia and lymphoma survivors: a systematic review. Leuk Lymphoma. 2018;59(2):381-97. https://doi.org/10.1080/10428194.2017. 1352097.

23. Mueller BA, Chow EJ, Kamineni A, Daling JR, Fraser A, Wiggins $\mathrm{CL}$, et al. Pregnancy outcomes in female childhood and adolescent cancer survivors: a linked cancer-birth registry analysis. Arch Pediatr Adolesc Med. 2009;163(10):879-86. https://doi.org/10. 1001/archpediatrics.2009.112.

24. van Dorp W, Haupt R, Anderson RA, Mulder RL, van den HeuvelEibrink MM, van Dulmen-den Broeder E, et al. Reproductive function and outcomes in female survivors of childhood, adolescent, and young adult cancer: a review. J Clin Oncol. 2018;36(21): 2169-80. https://doi.org/10.1200/jco.2017.76.3441.

25. Schuster T, Korte E, Schilling R, Holling H, Balcerek M, Borgmann-Staudt A. Ambulant health care utilisation among children of childhood cancer survivors in Germany. Support Care Cancer. 2020;28(2):787-95. https://doi.org/10.1007/s00520-01904861-7.

26. Hohmann C, Borgmann-Staudt A, Rendtorff R, Reinmuth S, Holzhausen S, Willich SN, et al. Patient counselling on the risk of infertility and its impact on childhood cancer survivors: results from a national survey. J Psychosoc Oncol. 2011;29(3):274-85. https:// doi.org/10.1080/07347332.2011.563344.

27. Calaminus GKP, Creutzig U, Langer T. VIVE - Langzeitbefragung ehemaliger Patienten mit Krebs im Kindes- und Jugendalter - Ein Verbundprojekt von TOS/DKKR/LESS/AG LQ. Klin Padiatr. 2012;224. https://doi.org/10.1055/s-0032-1306244.

28. Hölling H, Schlack R, Kamtsiuris P. Die KiGGS-Studie. Bundesweit repräsentative Längs- und Querschnittstudie zur Gesundheit von Kindern und Jugendlichen im Rahmen des Gesundheitsmonitorings am Robert Koch-Institut. Bundesgesundheitsbl. 2012;55(6-7):836-42. https://doi.org/10. 1007/s00103-012-1486-3.

29. World Health Organisation. International Statistical Classification of Diseases and Related Health Problems (10th Revision). https:// icd.who.int/browse10/2019/en. https://icd.who.int/browse10/2016/ en.

30. Steliarova-Foucher E, Stiller C, Lacour B, Kaatsch P. International classification of childhood cancer, third edition. Cancer. 2005;103(7):1457-67. https://doi.org/10.1002/cncr.20910.

31. Cohen J. Statistical power analysis for the behavioral sciences. 2nd edition ed. New York: Routledge 1988.

32. Brauns HSS, Steinmann S (2003) The CASMIN Educational classification in international comparative research. In: HoffmeyerZlotnik J.H.P. WC, editor. Advances in cross-national comparison. Springer, Boston, MA2003.

33. Blondel B, Kogan MD, Alexander GR, Dattani N, Kramer MS, Macfarlane A, et al. The impact of the increasing number of multiple births on the rates of preterm birth and low birthweight: an international study. Am J Public Health. 2002;92(8):1323-30. https://doi.org/10.2105/ajph.92.8.1323.

34. Blumenauer VCU, Fehr D, Fiedler K, Gnoth C, Krüssel JSKM, Ott A, et al. D.I.R-Annual 2017. J Reprod Med Endocrinol. 2018;15(56):216-49.

35. Melin J, Madanat-Harjuoja L, Heinavaara S, Malila N, Gissler M, Tiitinen A. Fertility treatments among female cancer survivors giving birth-a Finnish register-based study. Acta Oncol. 2017;56(8): 1089-93. https://doi.org/10.1080/0284186x.2017.1304653.

36. Oktay K, Harvey BE, Partridge AH, Quinn GP, Reinecke J, Taylor HS, et al. Fertility preservation in patients with cancer: ASCO clinical practice guideline update. J Clin Oncol. 2018;36(19):1994 2001. https://doi.org/10.1200/jco.2018.78.1914.

37. Balcerek M, Schilling R, Byrne J, Dirksen U, Cario H, FernandezGonzalez MJ, et al. Determinants of utilization of cryopreservation 
of germ cells in adolescent cancer patients in four European countries. Eur J Pediatr. 2020;179(1):51-60. https://doi.org/10.1007/ s00431-019-03459-9.

38. Borgmann-Staudt A, Kunstreich M, Schilling R, Balcerek M, Dirksen U, Cario H, et al. Fertility knowledge and associated empowerment following an educational intervention for adolescent cancer patients. Psychooncology. 2019;28(11):2218-25. https:// doi.org/10.1002/pon.5210.

39. Sunderam S, Kissin DM, Zhang Y, Folger SG, Boulet SL, Warner L, et al. Assisted reproductive technology surveillance-United States, 2016. MMWR Surveill Summ. 2019;68(4):1-23. https:// doi.org/10.15585/mmwr.ss6804a1.

40. Moore E, Blatt K, Chen A, Van Hook J, DeFranco EA. Relationship of trimester-specific smoking patterns and risk of preterm birth. Am J Obstet Gynecol. 2016;215(1):109.e1-6. https:// doi.org/10.1016/j.ajog.2016.01.167.

41. Sbrana M, Grandi C, Brazan M, Junquera N, Nascimento MS, Barbieri MA, et al. Alcohol consumption during pregnancy and perinatal results: a cohort study. Sao Paulo Med J. 2016;134(2): 146-52. https://doi.org/10.1590/1516-3180.2015.02040211.

42. Klein J, von dem Knesebeck O. Inequalities in health care utilization among migrants and non-migrants in Germany: a systematic review. Int J Equity Health. 2018;17(1):160. https://doi.org/10. 1186/s12939-018-0876-Z

43. David M, Borde T, Brenne S, Ramsauer B, Henrich W, Breckenkamp J, et al. Obstetric and perinatal outcomes among immigrant and non-immigrant women in Berlin, Germany. Arch Gynecol Obstet. 2017;296(4):745-62. https://doi.org/10.1007/ s00404-017-4450-5.

44. Raju TN. Moderately preterm, late preterm and early term infants: research needs. Clin Perinatol. 2013;40(4):791-7. https://doi.org/ 10.1016/j.clp.2013.07.010.

45. van de Loo L, van den Berg MH, Overbeek A, van Dijk M, Damen $\mathrm{L}$, Lambalk CB, et al. Uterine function, pregnancy complications, and pregnancy outcomes among female childhood cancer survivors. Fertil Steril. 2019;111(2):372-80. https://doi.org/10.1016/j. fertnstert.2018.10.016.

46. Io M, Council NR. Childhood Cancer survivorship: improving care and quality of life. Washington, DC: The National Academies Press; 2003.

47. Williams CL, Bunch KJ, Stiller CA, Murphy MF, Botting BJ, Wallace WH, et al. Cancer risk among children born after assisted conception. N Engl J Med. 2013;369(19):1819-27. https://doi.org/ 10.1056/NEJMoa1301675.

48. Spaan M, van den Belt-Dusebout AW, van den Heuvel-Eibrink MM, Hauptmann M, Lambalk CB, Burger CW, et al. Risk of cancer in children and young adults conceived by assisted reproductive technology. Hum Reprod. 2019;34(4):740-50. https://doi.org/10. 1093/humrep/dey394.
49. Hargreave M, Jensen A, Toender A, Andersen KK, Kjaer SK. Fertility treatment and childhood cancer risk: a systematic metaanalysis. Fertil Steril. 2013;100(1):150-61. https://doi.org/10. 1016/j.fertnstert.2013.03.017.

50. Hoorsan H, Mirmiran P, Chaichian S, Moradi Y, Hoorsan R, Jesmi F. Congenital malformations in infants of mothers undergoing assisted reproductive technologies: a systematic review and metaanalysis study. J Prev Med Public Health. 2017;50(6):347-60. https://doi.org/10.3961/jpmph.16.122.

51. van der Kooi ALF, Brewster DH, Wood R, Nowell S, Fischbacher C, van den Heuvel-Eibrink MM, et al. Perinatal risks in female cancer survivors: a population-based analysis. PLoS One. 2018;13(8):e0202805. https://doi.org/10.1371/journal.pone. 0202805 .

52. Seppanen VI, Artama MS, Malila NK, Pitkaniemi JM, Rantanen ME, Ritvanen AK, et al. Risk for congenital anomalies in offspring of childhood, adolescent and young adult cancer survivors. Int $\mathrm{J}$ Cancer. 2016;139(8):1721-30. https://doi.org/10.1002/ijc.30226.

53. Winther JF, Boice JD Jr, Frederiksen K, Bautz A, Mulvihill JJ, Stovall M, et al. Radiotherapy for childhood cancer and risk for congenital malformations in offspring: a population-based cohort study. Clin Genet. 2009;75(1):50-6. https://doi.org/10.1111/j. 1399-0004.2008.01109.x.

54. Signorello LB, Mulvihill JJ, Green DM, Munro HM, Stovall M, Weathers RE, et al. Congenital anomalies in the children of cancer survivors: a report from the childhood cancer survivor study. J Clin Oncol. 2012;30(3):239-45. https://doi.org/10.1200/jco.2011.37. 2938.

55. Winther JF, Boice JD Jr, Christensen J, Frederiksen K, Mulvihill JJ, Stovall M, et al. Hospitalizations among children of survivors of childhood and adolescent cancer: a population-based cohort study. Int J Cancer. 2010;127(12):2879-87. https://doi.org/10.1002/ijc. 25286.

56. Fuchs F, Monet B, Ducruet T, Chaillet N, Audibert F. Effect of maternal age on the risk of preterm birth: a large cohort study. PLoS One. 2018;13(1):e0191002. https://doi.org/10.1371/journal. pone.0191002.

57. Sukalich S, Mingione MJ, Glantz JC. Obstetric outcomes in overweight and obese adolescents. Am J Obstet Gynecol. 2006;195(3): 851-5. https://doi.org/10.1016/j.ajog.2006.06.070.

58. Goldenberg RL, Hauth JC, Andrews WW. Intrauterine infection and preterm delivery. N Engl J Med. 2000;342(20):1500-7. https://doi.org/10.1056/nejm200005183422007.

Publisher's note Springer Nature remains neutral with regard to jurisdictional claims in published maps and institutional affiliations. 